\title{
Potency-directed similarity searching using support vector machines
}

\author{
Kathrin Heikamp ${ }^{*}$, Anne M Wassermann, Jürgen Bajorath \\ From 7th German Conference on Chemoinformatics: 25 CIC-Workshop \\ Goslar, Germany. 6-8 November 2011
}

Searching for active compounds in screening databases is one of the main tasks in chemoinformatics [1,2]. For this purpose, different approaches have been developed, with an increasing interest in machine learning and data mining methods [3]. Among these, support vector machine (SVM) learning has proven to be a powerful search technique in many instances [3]. Several applications of SVMs have been reported that focus on compound ranking in similarity searching [4-6]. However, similarity search and machine learning methods that are commonly utilized for virtual screening generally do not take compound potency information into account. Regardless of the applied methods, one typically attempts to distinguish "active" from "inactive" compounds. With the exception of QSAR models adapted for compound screening, no approaches have thus far been introduced that incorporate potency information as a parameter and direct search calculations toward the recognition of potent hits. Here, an SVM approach for potency-directed virtual screening is introduced [7]. A newly designed structure-activity kernel and an SVM linear combination model take potency information of reference molecules into account. Applied to highthroughput screening data sets, this potency-directed SVM approach met or exceeded the recall performance of standard SVM ranking and led to a notable enrichment of highly potent hits in database selection sets.

\section{Published: 1 May 2012}

\section{References}

1. Stumpfe D, Bajorath J: Applied virtual screening: strategies, recommendations, and caveats. In Methods and Principles in Medicinal Chemistry. Virtual Screening. Principles, Challenges, and Practical Guidelines. Weinheim: Wiley-VCH;Sotriffer C 2011:73-103.

Department of Life Science Informatics, B-IT, LIMES Program Unit Chemical Biology and Medicinal Chemistry, Rheinische Friedrich-Wilhelms-Universität Bonn, Dahlmannstr. 2, D-53113 Bonn, Germany
2. Eckert $H$, Bajorath J: Molecular similarity analysis in virtual screening: foundations, limitations and novel approaches. Drug Discov Today 2007, 12:225-233.

3. Geppert H, Vogt M, Bajorath J: Current trends in ligand-based virtual screening: molecular representations, data mining methods, new application areas, and performance evaluation. J Chem Inf Model 2010, 50:205-216.

4. Jorissen RN, Gilson MK: Virtual screening of molecular databases using a support vector machine. J Chem Inf Model 2005, 45:549-561.

5. Wassermann AM, Geppert H, Bajorath J: Searching for target-selective compounds using different combinations of multiclass support vector machine ranking methods, kernel functions, and fingerprint descriptors. J Chem Inf Model 2009, 49:582-592.

6. Agarwal S, Dugar D, Sengupta S: Ranking chemical structures for drug discovery: a new machine learning approach. J Chem Inf Model 2010, 50:716-731.

7. Wassermann AM, Heikamp K, Bajorath J: Potency-directed similarity searching using support vector machines. Chem Biol Drug Des 2011, 77:30-38.

doi:10.1186/1758-2946-4-S1-P12

Cite this article as: Heikamp et al:: Potency-directed similarity searching using support vector machines. Journal of Cheminformatics 2012 4(Suppl 1):P12.

\section{Publish with ChemistryCentral and every scientist can read your work free of charge \\ "Open access provides opportunities to our colleagues in other parts of the globe, by allowing anyone to view the content free of charge." \\ W. Jeffery Hurst, The Hershey Company. \\ - available free of charge to the entire scientific community \\ - peer reviewed and published immediately upon acceptance \\ - cited in PubMed and archived on PubMed Central \\ - yours - you keep the copyright \\ Submit your manuscript here: \\ http://www.chemistrycentral.com/manuscript/

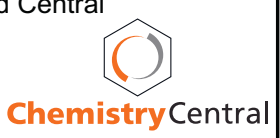

